\title{
Cariprazine for acute and maintenance treatment of adults with schizophrenia: an evidence-based review and place in therapy
}

This article was published in the following Dove Press journal: Neuropsychiatric Disease and Treatment

\section{Leslie Citrome}

Department of Psychiatry and Behavioral Sciences, New York Medical College, Valhalla, NY, USA

Correspondence: Leslie Citrome Department of Psychiatry and Behavioral Sciences, New York Medical College, 40 Sunshine Cottage Rd, Valhalla, NY 10595, USA

$\mathrm{Tel}+\mathrm{I} 845362208$ I

Fax +l 8453628745

Email citrome@cnsconsultant.com

\begin{abstract}
Cariprazine is an oral antipsychotic approved in the US and EU for the treatment of schizophrenia. Cariprazine differs from other antipsychotics in that it is a dopamine $\mathrm{D}_{3}$ - and $\mathrm{D}_{2}$-receptor partial agonist, with tenfold higher affinity for $\mathrm{D}_{3}$ receptors than for $\mathrm{D}_{2}$ receptors. Cariprazine is metabolized in two steps by CYP3A4 to didesmethyl-cariprazine (DDCAR). DDCAR has a long half-life of 1-3 weeks and is the predominant circulating active moiety. Efficacy and safety in persons with acute schizophrenia were assessed in four similarly designed, short-term, randomized, placebo-controlled clinical trials in nonelderly adults, with three studies considered positive and yielding a number needed to treat vs placebo for response (change from baseline $\geq 30 \%$ in Positive and Negative Syndrome Scale total score) of ten for the approved dose range of cariprazine $1.5-6 \mathrm{mg}$ /day. The most common adverse reactions were extrapyramidal symptoms ( $15 \%$ and $19 \%$ for $1.5-3$ and $4.5-6 \mathrm{mg}$ /day, respectively, vs $8 \%$ for placebo) and akathisia ( $9 \%$ and $12.5 \%$ for $1.5-3$ and $4.5-6 \mathrm{mg} /$ day, respectively, vs $4 \%$ for placebo). For the approved dose range, rates of discontinuation because of an adverse event were lower overall for patients receiving cariprazine vs placebo ( $9 \%$ vs $12 \%)$. Weight and metabolic profile appear favorable. Cariprazine does not increase prolactin levels or prolong the electrocardiographic QT interval. Cariprazine has also been found to be effective for the maintenance treatment of schizophrenia by delaying time to relapse when compared with placebo (HR 0.45). A 26-week randomized clinical trial evidenced superiority of cariprazine over risperidone for the treatment of predominantly negative symptoms in patients with schizophrenia. Cariprazine is also approved in the US for the acute treatment of manic or mixed episodes associated with bipolar I disorder in adults and is being studied for the treatment of bipolar I depression and major depressive disorder.
\end{abstract}

Keywords: cariprazine, didesmethyl-cariprazine, dopamine-receptor partial agonist, schizophrenia, dopamine D3 receptor

\section{Introduction}

Schizophrenia, a relatively common and chronic psychotic disorder, is notable for its marked heterogeneity in disease course and response to treatment, as well as differences among currently available psychopharmacological interventions. ${ }^{1-3}$ New medications are welcomed, in the hope that they can address the shortcomings of prior drugs in terms of both therapeutic targets ${ }^{4}$ and tolerability profile. ${ }^{5}$

Cariprazine is an antipsychotic medication that received initial approval by the US Food and Drug Administration (FDA) in $2015^{6}$ and approval by the European Medicines Agency in 2017. ${ }^{7}$ Although cariprazine is the third dopamine-receptor partial agonist antipsychotic to become generally available, it differs from the other two, aripiprazole 
and brexpiprazole, in several respects. ${ }^{89}$ This paper reviews the pharmacology, mode of action, and pharmacokinetics of cariprazine and the published peer-reviewed evidence supporting its use in persons with schizophrenia.

\section{Literature search}

A literature search was conducted on July 4, 2018, using the US National Library of Medicine's PubMed resource. Other sources of information included product labeling ${ }^{10}$ and the author's prior published reviews. ${ }^{11-13}$ Searching for "cariprazine" using PubMed yielded 125 records, of which 15 were original reports of clinical trial data in persons with schizophrenia, ${ }^{14-28} 24$ were medicinal chemistry or preclinical research reports, ${ }^{29-52} 9$ were original reports of cariprazine clinical trial data for disorders other than schizophrenia, ${ }^{53-61}$ and the remainder consisted of reviews, commentaries, or articles that did not appear directly relevant. Three metaanalyses were found that focused on cariprazine and included data for the treatment of schizophrenia. ${ }^{62-64}$

\section{Pharmacology, mode of action, and pharmacokinetics of cariprazine}

Current FDA-approved pharmacological interventions for schizophrenia focus on antagonism or partial agonism at the dopamine $\mathrm{D}_{2}$ receptor and, in the case of second-generation (atypical) antipsychotics, antagonism at the serotonin $5 \mathrm{HT}_{2 \mathrm{~A}}$ receptor. ${ }^{4}$ However, the antipsychotics differ in terms of their pharmacodynamic profile by secondary binding characteristics at other receptors, with some of these affinities often being more robust (ie, associated with a lower binding constant or $\mathrm{K}_{\mathrm{i}}$ ) than for dopamine $\mathrm{D}_{2}$ or serotonin $5 \mathrm{HT}_{2 \mathrm{~A}}$ receptors. ${ }^{65}$

Cariprazine is a dopamine $\mathrm{D}_{3}$ - and $\mathrm{D}_{2}$-receptor partial agonist with tenfold higher affinity for $\mathrm{D}_{3}$ receptors than for $\mathrm{D}_{2}$ receptors $\left(\mathrm{K}_{\mathrm{i}}\right.$ for $\mathrm{D}_{3}$ receptors $0.085 \mathrm{nM}$ vs $0.49 \mathrm{nM}$ and $0.69 \mathrm{nM}$ for the two types of $\mathrm{D}_{2}$ receptors assayed). ${ }^{10,13,30}$ Intrinsic activity of cariprazine at dopamine $\mathrm{D}_{2}$ receptors is numerically lower than that for aripiprazole..$^{33}$ Additional pharmacodynamic characteristics include partial agonism at the serotonin $5 \mathrm{HT}_{1 \mathrm{~A}}$ receptor $\left(\mathrm{K}_{\mathrm{i}} 2.6 \mathrm{nM}\right)$ and antagonism at $5 \mathrm{HT}_{2 \mathrm{~B}}$ and $5 \mathrm{HT}_{2 \mathrm{~A}}$ receptors with high and moderate binding affinity $\left(\mathrm{K}_{\mathrm{i}} 0.58\right.$ and $18.8 \mathrm{nM}$, respectively) and moderate affinity for the histamine $\mathrm{H}_{1}$ receptor, also as an antagonist $\left(\mathrm{K}_{\mathrm{i}} 23.2 \mathrm{nM}\right)$. Lower binding affinity has been noted for the serotonin $5 \mathrm{HT}_{2 \mathrm{C}}$ and $\alpha_{1 \mathrm{~A}}$-adrenergic receptors $\left(\mathrm{K}_{\mathrm{i}} 134\right.$ and $155 \mathrm{nM}$, respectively), and no appreciable affinity has been noted for cholinergic muscarinic receptors $\left(\mathrm{IC}_{50}>1,000 \mathrm{nM}\right)$. The three commercially available dopamine-receptor partial agonists (aripiprazole, brexpiprazole, and cariprazine) have differing receptor-binding profiles, making them distinct molecular entities (see Table 2 located in reference 8). ${ }^{8}$

A substantial amount of preclinical data is available supporting the potential therapeutic benefit of targeting dopamine $\mathrm{D}_{3}$ receptors. ${ }^{32,35,36,39,44,46,47}$ Theoretically, antagonism at $\mathrm{D}_{3}$ autoreceptors can enhance dopaminergic neurotransmission, especially in such brain areas as the prefrontal cortex, where dopamine release appears to be controlled by $\mathrm{D}_{3}$ receptors. ${ }^{66}$ With disinhibition of dopamine release, cortical circuits can be "tuned" to improve cognition, mood, and negative symptoms. ${ }^{67} \mathrm{In}$ this process, acetylcholine release in the prefrontal cortex may be enhanced as well, which could also contribute to procognitive actions. ${ }^{66}$

The pharmacokinetic profile of cariprazine is markedly different than that of other currently marketed antipsychotics. Although extensive metabolism by CYP3A4 (and to a lesser extent by CYP2D6) is not unusual, the ultimate active metabolite, didesmethyl-cariprazine (DDCAR), has a long half-life, described in product labeling as $1-3$ weeks. ${ }^{10}$ Therefore, DDCAR is the predominant circulating active moiety. Following a single dose of $1 \mathrm{mg}$ cariprazine, DDCAR remains detectable at 8 weeks postdose. This has important implications in terms of dosing and interpretation of clinical trial results, which will be discussed later. DDCAR has an in vitro receptor-binding profile similar to cariprazine $\left(\mathrm{K}_{\mathrm{i}} 0.057 \mathrm{nM}\right.$ for dopamine $\mathrm{D}_{3}$ receptors and 1.41 and $2.64 \mathrm{nM}$ for the two types of $\mathrm{D}_{2}$ receptors assayed); $;, 10$ however, intrinsic activity at the dopamine $\mathrm{D}_{2}$ receptor for DDCAR has been reported to be about half that for cariprazine. ${ }^{33}$

Additional details regarding the pharmacokinetic profile of cariprazine can be found in a report of a multicenter, randomized, open-label, parallel-group, fixed-dose $(3,6$, or $9 \mathrm{mg} /$ day) study of 28 -week duration ( $\leq 4$-week observation, 12-week open-label treatment, and 12-week follow-up), where cariprazine was administered once daily to 38 adult patients with schizophrenia. ${ }^{18}$ Steady state was reached within 1-2 weeks for cariprazine and DCAR (the intermediate active metabolite that gets transformed to DDCAR), 4 weeks for DDCAR, and 3 weeks for total active moieties. Cariprazine and DCAR levels decreased $>90 \%$ within 1 week after the last dose, in contrast to DDCAR, which had decreased $\sim 50 \%$ at 1 week. Total active moieties decreased $\sim 90 \%$ within 4 weeks. In this study, the terminal half-lives of cariprazine, DCAR, and DDCAR ranged 32-68, 30-38, and 314-446 hours ( $\sim 2-3$ weeks), respectively. The effective half-life (calculated from time to steady state) of total active moieties was 
approximately 1 week. Exposure was dose proportional over the range of 3-9 mg/day. The product label notes that mean concentrations of DCAR and DDCAR are approximately $30 \%$ and $400 \%$, respectively, of cariprazine concentrations by the end of 12 -week treatment..$^{10}$ Figure 1 illustrates the key points regarding concentrations of cariprazine, DCAR, and DDCAR over time.

Time to peak concentration of cariprazine is $3-6$ hours. ${ }^{10,18}$ Administration of a single dose of $1.5 \mathrm{mg}$ cariprazine with a high-fat meal does not significantly affect maximum concentration or area under the concentration curve of cariprazine or DCAR. ${ }^{10}$ Cariprazine and its major active metabolites are highly bound (91\%-97\%) to plasma proteins. ${ }^{10}$

Drug-drug interactions involving a strong CYP3A4 inhibitor will necessitate reduction of the cariprazine dose by half (for patients already taking $4.5 \mathrm{mg} /$ day, dosage should be reduced to 1.5 or $3 \mathrm{mg} / \mathrm{day}$, and for patients taking $1.5 \mathrm{mg}$ daily, the dosing regimen should be adjusted to every other day). ${ }^{10}$ When initiating cariprazine in a person already on a strong CYP3A4 inhibitor, the patient should be administered $1.5 \mathrm{mg}$ on days 1 and 3, with no dose administered on day 2 . From day 4 onward, the dose should be administered at $1.5 \mathrm{mg} /$ day, then increased to a maximum dose of $3 \mathrm{mg} /$ day. When the CYP3A4 inhibitor is withdrawn, cariprazine dosage may need to be increased. ${ }^{10}$ Concomitant use of cariprazine and a CYP3A4 inducer has not been evaluated and is not recommended, because the net effect on the active drug and metabolites is unclear. ${ }^{10}$

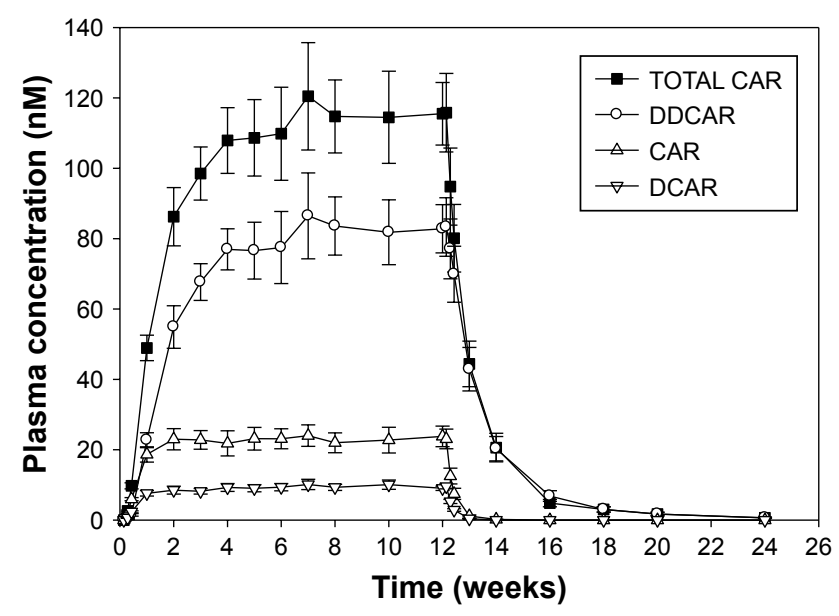

Figure I Plasma concentration at trough (mean $\pm \mathrm{SE}$ )-time profile during and following I2-weeks of treatment with cariprazine $6 \mathrm{mg} /$ day.

Notes: Reproduced from the product label. ${ }^{10}$ DDCAR is the predominant circulating moiety, representing about $70 \%$ of the total exposure. When treatment is discontinued, DDCAR concentrations persist longer than for cariprazine or DCAR.

Abbreviations: CAR, cariprazine; DDCAR, didesmethyl-cariprazine; total CAR, summed concentration of cariprazine, DCAR, and DDCAR.
No dosage adjustment is required in the presence of CYP2D6 inhibitors or in persons who are poor CYP2D6 metabolizers. ${ }^{10}$ For patients with mild-moderate hepatic or renal impairment, no dosage adjustment is required. Cariprazine has not been studied in patients with severe hepatic or renal impairment, and is thus not recommended for such patients. ${ }^{10}$ No dosage adjustment for cariprazine is required based on age, sex, race, or smoking status. ${ }^{10}$ Although doses of cariprazine $\leq 12 \mathrm{mg}$ /day have been assessed in the clinical trials described herein, the recommended maximum dose is $6 \mathrm{mg} /$ day, because of a dose-related increase in certain adverse reactions, particularly at doses $>6 \mathrm{mg} /$ day. ${ }^{10}$

\section{Efficacy and safety in acute schizophrenia}

Four similarly designed, short-term, randomized, placebocontrolled clinical trials in nonelderly adults with acute exacerbations of schizophrenia have been conducted and published, ${ }^{14-17}$ of which three are included in section 14 of the product label and considered supportive of efficacy. ${ }^{10,15-17}$ Table 1 provides an overview of all four studies. For consistency, statistical outcomes based on the mixed-effect model for repeated measures are presented for all studies, even though it was the primary method of analysis for only the two phase III studies. ${ }^{16,17}$

In the three supportive pivotal trials, ${ }^{15-17}$ the mean age of participants was 38 years, $\sim 70 \%$ were male, and $\sim 40 \%$ were white. Mean body-mass index was $26 \mathrm{~kg} / \mathrm{m}^{2}$. A little more than $50 \%$ of subjects were in the US. The mean baseline Positive and Negative Syndrome Scale (PANSS) total score was about 97. All tested doses of cariprazine - 1.5, 3, 4.5, 6, 3-6, and 6-9 mg/day - were superior to placebo on reduction in PANSS total score, the primary outcome measure for each of the trials. Patients were also assessed using the Clinical Global Impression - severity (CGI-S) score, which was the key secondary end-point measure. Cariprazine was consistently superior to placebo on this outcome as well. A pooled analysis of CGI-S scores examining shifts, such as from extremely or severely ill (CGI-S $\geq 5$ ) to mildly ill or better (CGI-S $\leq 3$ ), demonstrated an advantage for cariprazine over placebo (OR 3.4, 95\% CI 1.5-7.9). ${ }^{26}$ Of clinical relevance are observed effect sizes for antipsychotic response, as defined by change from baseline $\geq 30 \%$ in PANSS total score. ${ }^{15-17}$ Pooling together data for the approved dose range of cariprazine (1.5-6 mg/day) revealed a number needed to treat (NNT) vs placebo of ten (95\% CI 7-19); ${ }^{11}$ however, in one trial the NNT vs placebo for response was as robust as six. ${ }^{15}$ Indirect comparisons with other antipsychotics 


\begin{tabular}{|c|c|c|c|}
\hline 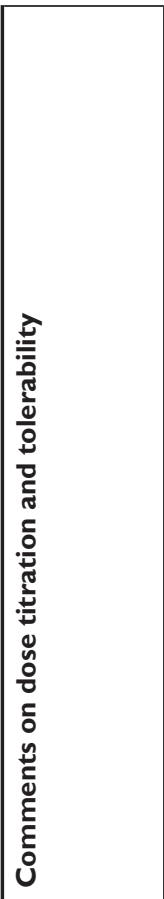 & 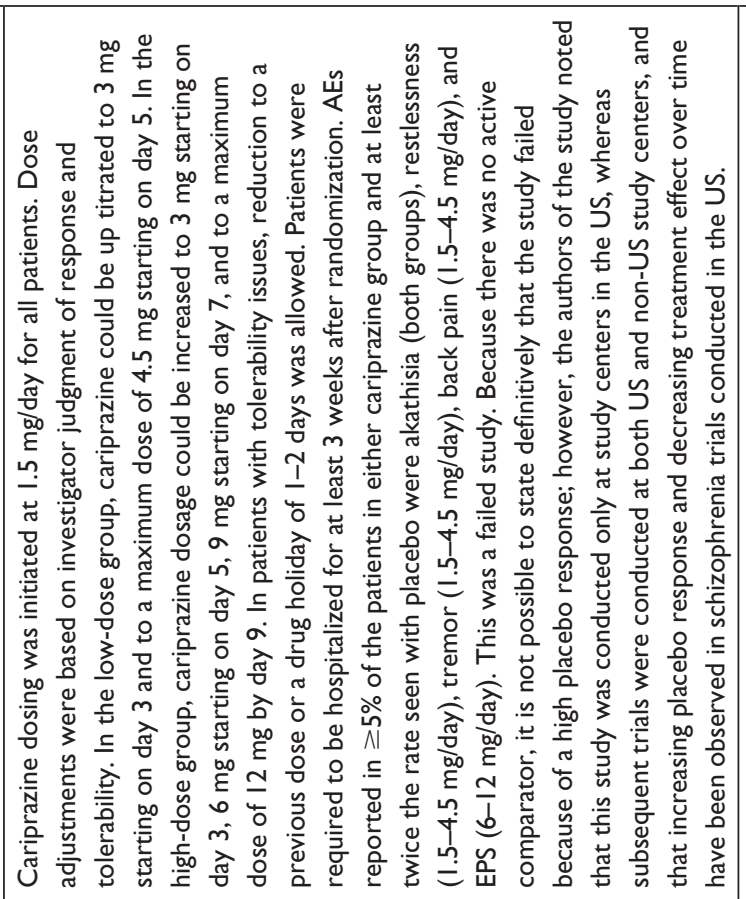 & 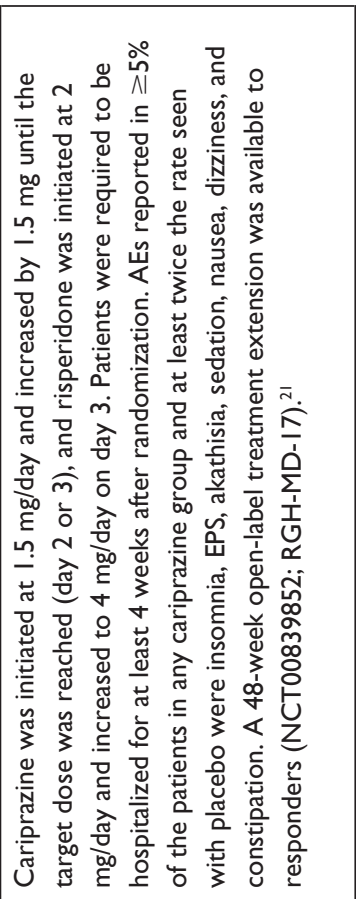 & 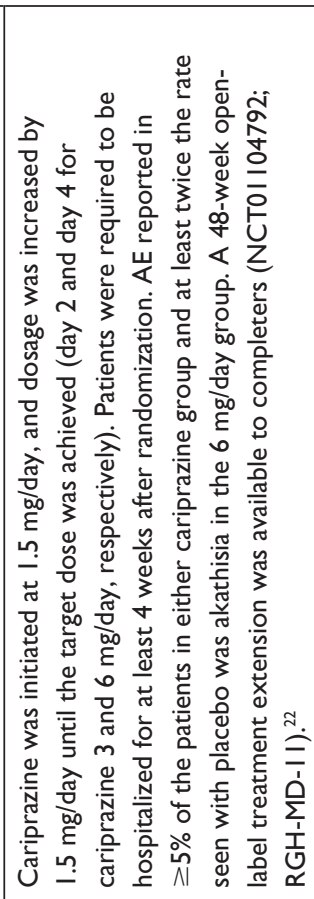 \\
\hline 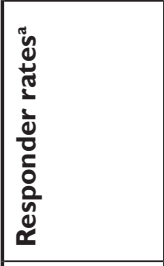 & 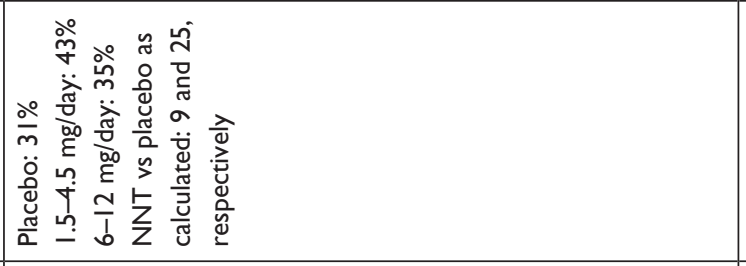 & 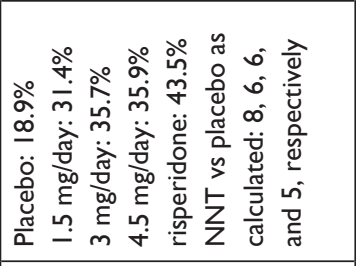 & 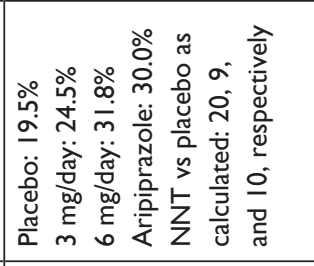 \\
\hline 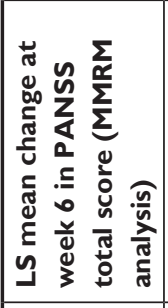 & 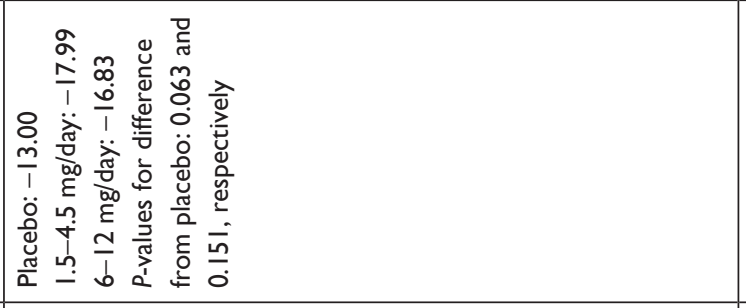 & 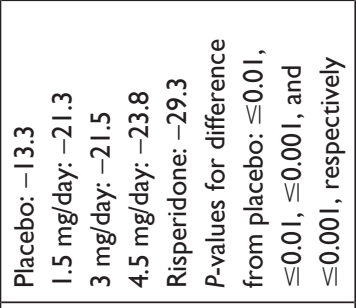 & 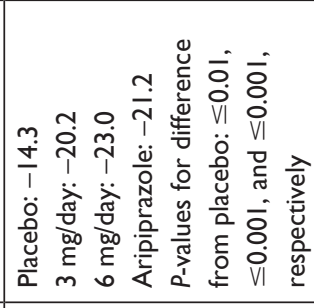 \\
\hline 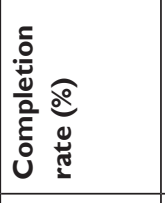 & 芦 & t & 6 \\
\hline 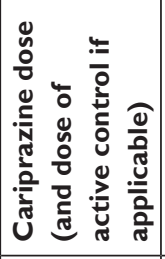 & 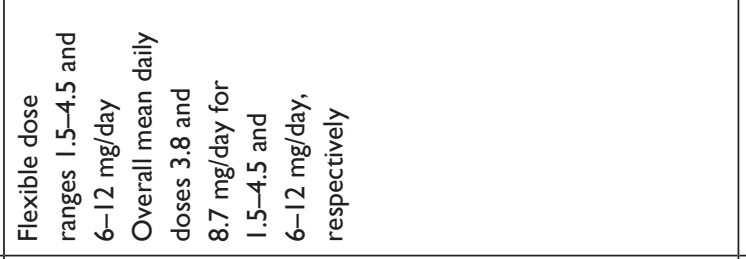 & 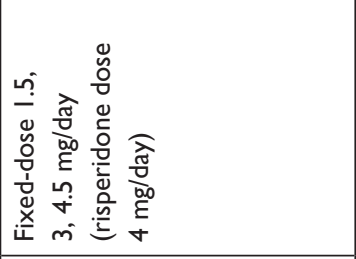 & 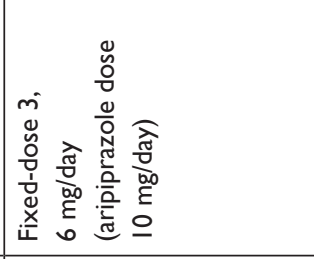 \\
\hline 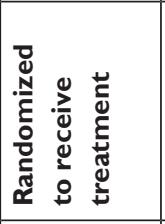 & 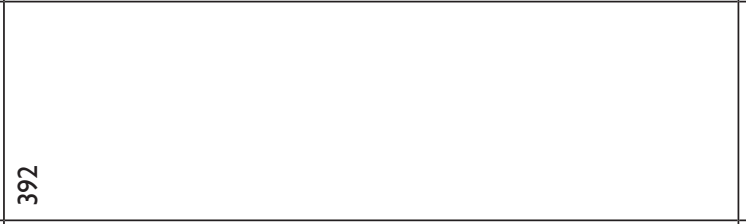 & న̃ & 6 \\
\hline $\begin{array}{l}\text { ते } \\
\text { जे }\end{array}$ & 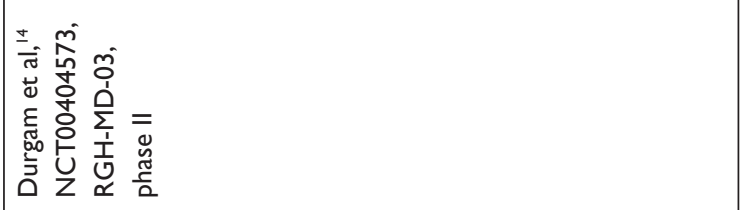 & 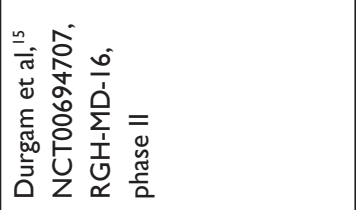 & 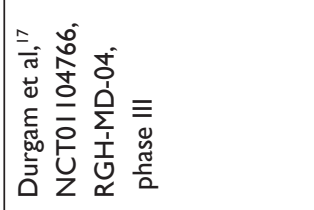 \\
\hline
\end{tabular}




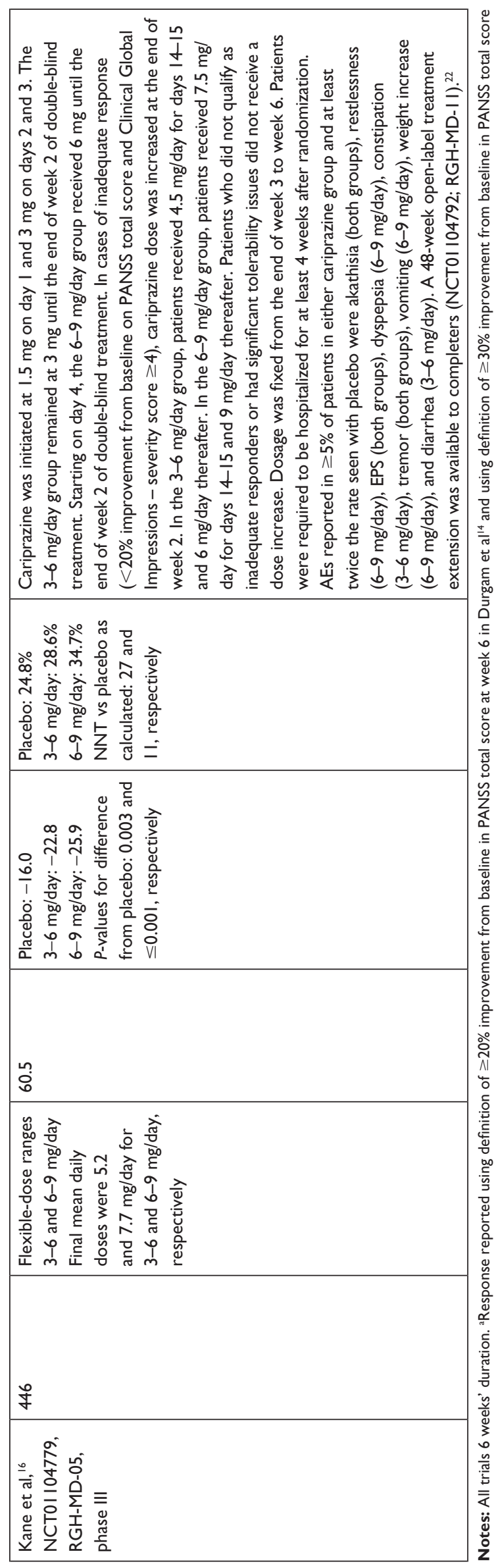

are hampered by lack of a uniform definition for response; however, similar criteria used for the assessment of NNT vs placebo for aripiprazole and brexpiprazole (response defined as change from baseline $\geq 30 \%$ in PANSS total score or a CGI - improvement score of 1 [very much improved] or 2 [much improved]) in similar acute studies yielded NNT values of eight for aripiprazole and seven for brexpiprazole, with overlap of $95 \%$ CIs. ${ }^{8}$ A tutorial on NNT can be found in a prior review. ${ }^{11}$

Cariprazine has also been evaluated post hoc for specific antihostility effects in patients with schizophrenia. ${ }^{25}$ Data were pooled from the three positive acute studies, ${ }^{15-17}$ and the principal outcome was mean change from baseline to week 6 on the PANSS hostility item. Significantly greater improvement in hostility was seen in favor of cariprazinetreated patients compared with placebo-treated patients. The improvement associated with cariprazine appeared to be partially independent of improvement in PANSS positive symptoms, such as hallucinations and delusions, independent of the presence or absence of sedation, and was greater in magnitude in patients with higher levels of hostility at baseline.

Two meta-analyses are available that have examined the efficacy of cariprazine in acute schizophrenia ${ }^{63,64}$ using the four studies available. ${ }^{14-17}$ In one meta-analysis,${ }^{63}$ low and high ( $\geq 6 \mathrm{mg} /$ day) doses were tested separately, and both high and low cariprazine doses demonstrated superiority to placebo in all symptom domains (PANSS total score, PANSS positive, PANSS negative, PANSS response, Schizophrenia Quality of Life Scale - revision 4, and CGI improvement). No differences were found between high and low doses on these measures. The standardized mean difference vs placebo showed a modest impact on overall symptoms compared with meta-analytic results for other antipsychotics (effects similar to lurasidone, asenapine, ziprasidone, and aripiprazole, but less than for risperidone, quetiapine, and olanzapine). The other meta-analysis ${ }^{64}$ also demonstrated superiority of cariprazine over placebo for PANSS total, PANSS positive, and PANSS negative score changes from baseline.

Safety and tolerability data collected during the four acute trials in schizophrenia included the incidence of spontaneously reported adverse events (briefly summarized in Table 1 by study), body weight, laboratory measurements, vital signs, electrocardiography, and movement-disorder scales. For cariprazine doses of $1.5-6 \mathrm{mg} /$ day, rates of discontinuation because of an adverse event were overall lower for patients receiving cariprazine vs placebo ( $9 \%$ vs $12 \%) .{ }^{8}$ As per the product label, there was no single adverse reaction leading to discontinuation that occurred at a rate $\geq 2 \%$ 
in cariprazine-treated patients and at least twice the rate of placebo. ${ }^{10}$ A pooled analysis of safety and tolerability is available using three modal daily dose groups (ie, most frequent dose taken by a patient during double-blind treatment): 1.5-3, 4.5-6, and 9-12 mg/day. ${ }^{24}$ The overall incidence of treatment-emergent adverse events vs placebo was similar for cariprazine 1.5-3 mg/day, but higher for cariprazine 4.5-6 and 9-12 mg/day, with a dose-response relationship observed for akathisia, extrapyramidal symptoms (EPS), and diastolic blood pressure. Regarding the latter, a shift from normotensive to stage I hypertension was observed in $2.0 \%$ of patients receiving placebo compared with $1.1 \%$, $2.8 \%$, and $6.8 \%$ for patients receiving $1.5-3,4.5-6$, and 9-12 mg/day of cariprazine, respectively. Patients in the modal dose $>6 \mathrm{mg}$ /day group showed a higher likelihood for weight increase, as well as higher rates of CPK and transaminase elevations. These observations on doses $>6 \mathrm{mg} /$ day resulted in the FDA approving a recommended dose range for schizophrenia of $1.5-6 \mathrm{mg} /$ day. ${ }^{10,24}$

From the pooled data, mean changes in metabolic parameters were generally similar in cariprazine-treated and placebo-treated patients. ${ }^{24}$ No prolactin level increase or QTc value $>500 \mathrm{~ms}$ was noted. The incidence of orthostatic hypotension was similar for placebo (12.3\%) and cariprazine (13.4\%). No syncopal episodes were reported. Weight increase with cariprazine overall was $1.1 \mathrm{~kg}$ compared with $0.3 \mathrm{~kg}$ for placebo-treated patients. Weight increase $\geq 7 \%$ occurred in $9.2 \%$ of cariprazine-treated patients and $4.7 \%$ of placebo-treated patients at any time during double-blind treatment, for a calculated number needed to harm $(\mathrm{NNH})$ vs placebo of 23 (95\% CI 15-46). Within the recommended dose range of 1.5-6 mg/day, mean weight gain was $\leq 1 \mathrm{~kg}$ for cariprazine, and proportions with $\geq 7 \%$ increase in weight were $7.6 \%$ and $7.7 \%$ for the $1.5-3$ and $4.5-6 \mathrm{mg} /$ day groups, respectively, yielding a NNH vs placebo of 35 (95\% CI 18-1,248) and 34 (95\% CI 18-443), respectively.

Of note, both mean weight change and shifts in weight $\geq 7 \%$ were larger in the $9-12 \mathrm{mg}$ /day dose group, with a rate of $17.2 \%$ and resulting in a calculated NNH vs placebo of 8 (95\% CI 6-15); however, there was no corresponding alteration in fasting triglycerides, as noted by a shift in rate from fasting triglycerides normal/borderline ( $<200 \mathrm{mg} /$ day/L) to high ( $\geq 200 \mathrm{mg} /$ day/L) of $14.2 \%$ for patients receiving placebo compared with $11.9 \%, 10.8 \%$, and $11.8 \%$ of patients receiving modal doses of cariprazine $1.5-3$, 4.5-6, and 9-12 mg/day, respectively. Similarly, shift rates for total, low-density lipoprotein (LDL) and high-density lipoprotein (HDL) cholesterol were not higher for cariprazine compared to placebo. Shift rates for fasting glucose normal $(<100 \mathrm{mg} / \mathrm{day} / \mathrm{L})$ to high $(\geq 126 \mathrm{mg} /$ day/L) were $6.7 \%$ for placebo compared with $7.4 \%, 9.8 \%$, and $2.7 \%$ of patients receiving modal doses of cariprazine $1.5-3,4.5-6$, and 9-12 mg/day, respectively, and thus did not follow a dose response. Difficult to interpret without more context is an absolute increase for fasting glucose $\geq 10 \mathrm{mg} /$ day/L, found in $35.2 \%, 41.3 \%, 49.8 \%$, and $50.3 \%$ of patients receiving placebo or modal doses of cariprazine 1.5-3, 4.5-6, and 9-12 mg/day, respectively. As found in a large epidemiological study, elevated fasting glucose level within the normal range can be an independent predictor of cardiovascular disease in men and of type 2 diabetes mellitus in both women and men. ${ }^{68}$

Table 2 is a list of spontaneously reported adverse events associated with the use of cariprazine (incidence $\geq 5 \%$ in any single cariprazine modal dose group and cariprazine incidence greater than placebo) observed in acute trials in schizophrenia and reported in product labeling ${ }^{10}$ and the published pooled analysis, ${ }^{24}$ together with their respective values for NNH vs placebo. As per the product label, the most common adverse reactions (incidence $\geq 5 \%$ and double or more the rate of placebo) for patients with schizophrenia were EPS and akathisia. Within the dose range of 4.5-6 mg/day, NNH values vs placebo were as strong as 9 (95\% CI 7-14) for EPS and 12 (95\% CI 9-18) for akathisia. The product label notes that adverse events may first appear several weeks after the initiation of treatment, probably because plasma levels of cariprazine and its major metabolites accumulate over time. ${ }^{10}$

Published tolerability data focusing on only cariprazine $1.5 \mathrm{mg} /$ day are limited to one of the acute clinical trials. ${ }^{15}$ Table 3 provides NNH values vs placebo for adverse events reported in that trial using two methods: comparison with the placebo group from that study alone and comparison with placebo groups pooled across the four acute studies. ${ }^{24}$ In general, cariprazine $1.5 \mathrm{mg} /$ day appears well tolerated. The strongest NNH values observed were for constipation when compared with placebo from the single study (NNH 16, 95\% CI 9-133) and akathisia when compared with placebo data pooled from all four available studies (NNH 19, 95\% CI 10-209). The NNH value for akathisia for the $1.5 \mathrm{mg} /$ day dose is about the same as for the 1.5-3 mg/day modal dose group (Table 2).

A meta-analysis is available of the tolerability and safety profile of cariprazine in the management of any mental disorder. ${ }^{62}$ Included in the meta-analysis are data from nine randomized clinical trials of up to 8 weeks in duration, including 


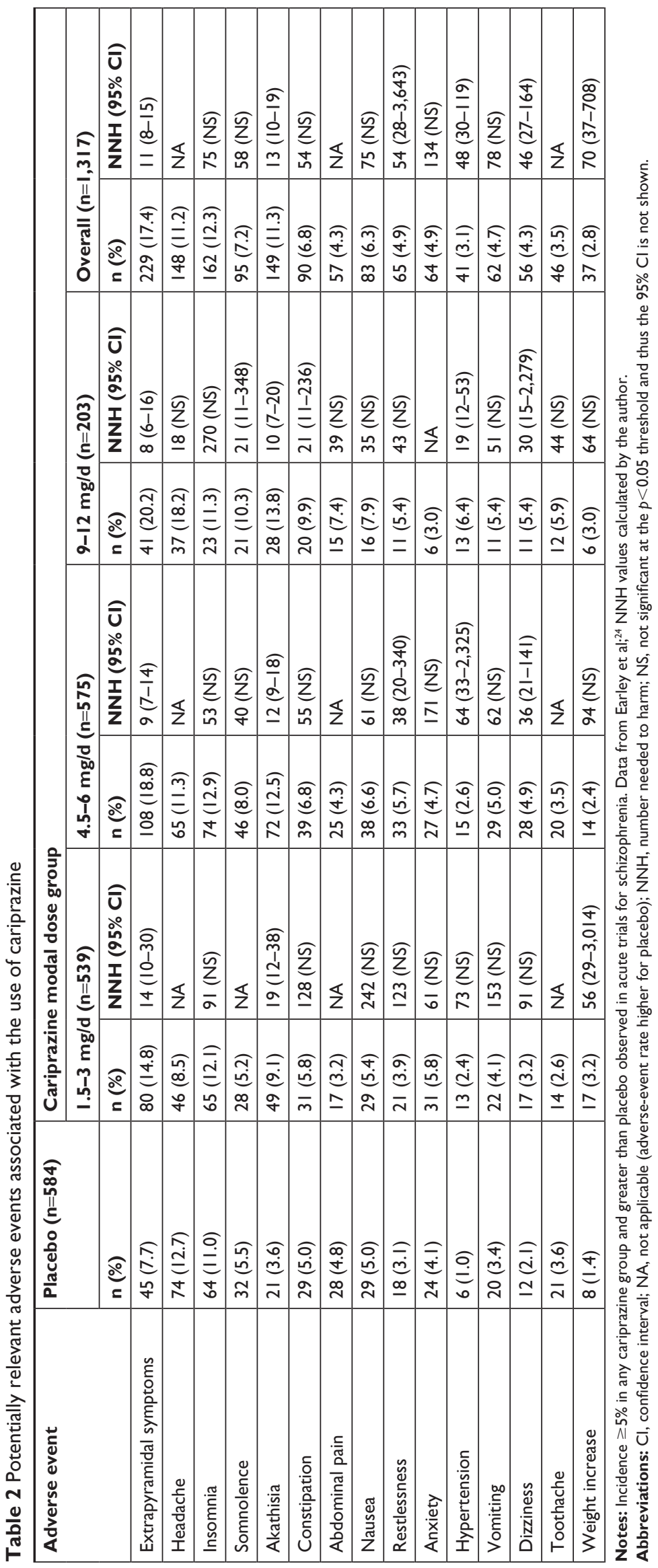


Table 3 Potentially relevant adverse events associated with the use of cariprazine $1.5 \mathrm{mg} /$ day as observed in Durgam et al ${ }^{15, a}$

\begin{tabular}{|c|c|c|c|c|c|}
\hline \multirow[t]{2}{*}{ Adverse event } & \multirow{2}{*}{$\begin{array}{l}\text { Cariprazine } \\
1.5 \text { mg/day }(\mathrm{n}=\mid 45) \\
\text { n (\%) }\end{array}$} & \multicolumn{2}{|c|}{ Placebo group ${ }^{15}(n=|5|)$} & \multicolumn{2}{|c|}{ Pooled placebo group ${ }^{24}(n=584)$} \\
\hline & & n (\%) & NNH (95\% Cl) & n (\%) & NNH $(95 \% \mathrm{Cl})$ \\
\hline Extrapyramidal symptoms & $13(9.0)$ & $7(4.6)$ & 24 (NS) & $45(7.7)$ & 80 (NS) \\
\hline Headache & $16(11.0)$ & $16(10.6)$ & 229 (NS) & $74(12.7)$ & NA \\
\hline Insomnia & $15(10.3)$ & II (7.3) & 33 (NS) & $64(11.0)$ & NA \\
\hline Somnolence or sedation & $7(4.8)$ & $5(3.3)$ & 66 (NS) & $32(5.5)$ & NA \\
\hline Akathisia & $13(9.0)$ & $7(4.6)$ & 24 (NS) & $21(3.6)$ & $19(10-209)$ \\
\hline Constipation & $14(9.7)$ & $5(3.3)$ & $16(9-133)$ & $29(5.0)$ & 22 (NS) \\
\hline Nausea & $7(4.8)$ & $5(3.3)$ & 66 (NS) & $29(5.0)$ & NA \\
\hline Anxiety & $6(4.1)$ & $5(3.3)$ & I2I (NS) & $24(4.1)$ & 3,529 (NS) \\
\hline Vomiting & $4(2.8)$ & $5(3.3)$ & NA & $20(3.4)$ & NA \\
\hline Dizziness & $5(3.4)$ & $3(2.0)$ & 69 (NS) & $12(2.1)$ & 72 (NS) \\
\hline Weight increased & $3(2.1)$ & $\mathrm{I}(0.7)$ & 72 (NS) & $8(1.4)$ & 143 (NS) \\
\hline
\end{tabular}

Note: ${ }^{2}$ Data for pooled placebo group was taken from Earley et $\mathrm{a}^{24}$ and $\mathrm{NNH}$ values were calculated by the author.

Abbreviations: $\mathrm{Cl}$, confidence interval; NA, not applicable (adverse-event rate higher for placebo); NNH, number needed to harm; $\mathrm{NS}$, not significant at the $p<0.05$ threshold and thus the $95 \% \mathrm{Cl}$ is not shown.

the four acute studies in patients with schizophrenia, ${ }^{14-17}$ the three pivotal studies for acute mania, ${ }^{53-55}$ and a study in bipolar depression, ${ }^{60}$ as well as a study in major depressive disorder, ${ }^{61}$ for a total of 4,324 subjects. Consistent with the data already presented for short-term studies in acute schizophrenia, the risk of discontinuation due to adverse events for cariprazine was similar to that for placebo (RR $1.13,95 \% \mathrm{CI}$ 0.77-1.66). Across all the studies, cariprazine was associated with higher risks of EPS-related events than placebo, including risk of akathisia (RR 3.92, 95\% CI 2.83-5.43), tremor (RR 2.41, 95\% CI 1.53-3.79), and restlessness (RR $2.17,95 \%$ CI 1.38-3.40). The cariprazine-treatment group was more likely to have clinically significant weight gain (RR 1.68, 95\% CI 1.12-2.52), but no statistically significant differences in results were found in other metabolic parameters or cardiovascular-related events. There were no statistically significant effects on prolactin level.

\section{Longer term safety}

A single-arm, open-label, extension study evaluated the longterm safety and tolerability of cariprazine $1.5-4.5 \mathrm{mg}$ /day in 93 patients with schizophrenia. ${ }^{21}$ Participants had completed the acute study that examined fixed doses of cariprazine 1.5, 3 , and $4.5 \mathrm{mg} / \mathrm{day},{ }_{15}$ and were also required to have responded to treatment (as defined by CGI-S $\leq 3$ and $\geq 20 \%$ reduction in PANSS total score) in that study. Approximately 50\% of patients completed the 48 weeks of open-label treatment. Cariprazine $4.5 \mathrm{mg}$ /day was the final dose for $70 \%$ of patients and was also the modal dose in $67.7 \% ; 24.7 \%$ and $7.5 \%$ of patients had modal daily doses of 3 and $1.5 \mathrm{mg} /$ day, respectively. Common adverse events included were akathisia (14\%), insomnia (14\%), and weight increase (12\%); $11 \%$ discontinued due to adverse events, none being akathisia or weight gain, and one patient discontinued because of insomnia. Mean changes in metabolic parameters were generally small and not clinically relevant. No patients shifted from normal/borderline levels of total or LDL cholesterol to high levels. Shifts from normal HDL-cholesterol levels to low levels occurred in about $23 \%$ of patients. About $14 \%$ of patients shifted from normal/borderline to high levels of triglycerides and about $4 \%$ with normal fasting glucose levels at baseline shifted to high levels. About $29 \%$ of patients had an increase in fasting glucose $\geq 10 \mathrm{mg} / \mathrm{day} / \mathrm{L}$. Mean body weight increased by $1.9 \mathrm{~kg}$ from the start of the lead-in study to the end of the extension study. Potentially clinically significant weight gain ( $\geq 7 \%$ increase from lead-in baseline) was experienced by $33 \%$ of patients, and $5 \%$ experienced weight increase $\geq 15 \%$. Most patients who experienced $\geq 7 \%$ weight increase were normal or underweight at baseline. There were no discontinuations associated with change in metabolic parameters or body weight. Prolactin elevation or clinically significant changes in cardiovascular parameters were not observed. No patient had a QTc increase $\geq 60 \mathrm{~ms}$ or a postbaseline value $>500 \mathrm{~ms}$. There were no clinically significant changes in ophthalmologic parameters, including intraocular pressure, color discrimination, visual acuity, or lens opacity. An adverse event of cataract was noted; however, this resolved during the study, was not felt to represent an actual pathological event, and was likely due to variability on the part of the examiner. 
A second open-label study evaluated the long-term safety and tolerability of cariprazine 3-9 $\mathrm{mg} /$ day in 586 patients with schizophrenia. ${ }^{22}$ Participants included both new patients $(n=235)$ and patients who had completed one of the two phase III acute studies $(\mathrm{n}=351) \cdot{ }^{16,17}$ Approximately $39 \%$ of patients completed the 48 weeks of open-label treatment. The most frequent modal daily dose was cariprazine $6 \mathrm{mg}$ /day (50.9\%), followed by $9 \mathrm{mg}$ /day (25.3\%) and $3 \mathrm{mg} /$ day $(22.9 \%)$. Common adverse events included were akathisia $(16 \%)$, headache $(13 \%)$, insomnia $(13 \%)$, and weight increase (10\%); $12.5 \%$ discontinued due to adverse events, with $<1 \%$ discontinuing due to akathisia. Mean cholesterol and triglyceride levels decreased; however, an increase of almost $5 \mathrm{mg} /$ day/L in glucose was observed. Shifts from normal/borderline to high cholesterol levels were observed in about $5 \%$ of patients, shifts from normal/borderline to high LDL-cholesterol levels were observed in about 3\% of patients, shifts from normal to low HDL-cholesterol levels were observed in about $12 \%$ of patients, shifts from normal/borderline to high triglyceride levels were observed in about $8 \%$ of patients, and for fasting glucose, shifts from normal/impaired to high levels were observed in about $6 \%$ of patients. Mean body weight increased by $1.5 \mathrm{~kg}$ from the start of the lead-in study to the end of the extension study. About $26 \%$ of patients had $\geq 7 \%$ increase from baseline in body weight, with patients categorized as underweight at baseline having the highest percentage of clinically significant weight gain $(40 \%)$.

Prolactin elevation or clinically significant changes in cardiovascular parameters were not observed. No retinal toxicity or cataracts were observed. One $(0.2 \%)$ patient had a postbaseline $\mathrm{QTcF}$ value $>500 \mathrm{~ms}$, and three $(0.5 \%)$ patients had QTcB postbaseline values $>500 \mathrm{~ms}$. An increase from baseline $>60 \mathrm{~ms}$ in QTcF or QTcB values occurred in two $(0.3 \%)$ and seven $(1.2 \%)$ patients, respectively. Pooled data from both 48 -week open-label safety studies ${ }^{21,22}$ are reported separately in a third publication..$^{23}$ The pattern of results remain the same as described earlier.

\section{Relapse prevention}

A supplemental new-drug application for cariprazine for the maintenance treatment of adults with schizophrenia was approved by the FDA in November 2017, ${ }^{69}$ based on a placebo-controlled, randomized withdrawal study in nonelderly adult patients with schizophrenia. ${ }^{19,20}$ See also Table 4. To participate in the trial, patients were required to be acutely ill at screening. During the 20 -week open-label treatment phase, patients received cariprazine 3-9 $\mathrm{mg}$ /day (starting at $1.5 \mathrm{mg} /$ day on day 1 ). In order to be randomized to either continue cariprazine or to receive placebo, patients were required to meet prespecified stability criteria. Once randomized, the double-blind phase consisted of 26-72 weeks of fixed-dose treatment. The primary efficacy outcome was time to first relapse during the double-blind phase. Relapse was defined as meeting any of several operational criteria (worsening of symptom scores, psychiatric hospitalization, aggressive/violent behavior, or suicidal risk). A total of 264 patients of 765 (34.5\%) completed the open-label phase, and 200 patients were randomized. Demographic and baseline characteristics of the participants entering the open-label phase were similar to those for the acute shortterm trials described earlier. Baseline PANSS score at the start of the double-blind phase was 51. At randomization, 14 patients were taking cariprazine $3 \mathrm{mg} /$ day, 37 patients were taking $6 \mathrm{mg} / \mathrm{day}$, and 50 patients were taking $9 \mathrm{mg} /$ day. Based on Kaplan-Meier analysis, time to relapse was significantly longer for patients who continued cariprazine than for patients randomized to placebo (HR $0.45,95 \% \mathrm{CI}$ $0.28-0.73$ ). Observed relapse rates were $24.8 \%$ for cariprazine vs $47.5 \%$ for placebo, for a NNT of five ( $95 \%$ CI $3-11$ ). The study protocol had the provision that subjects should meet the specified relapse criterion at a second assessment to be conducted 4-7 days after first meeting the criterion; however, the principal investigator had the discretion not to perform this second assessment based on safety reasons. Therefore, a sensitivity analysis that ensured that the first date of relapse was consistently applied was conducted in response to an FDA request, ${ }^{20}$ and the results of this are contained in product labeling ${ }^{10}$ (HR 0.52, 95\% CI 0.33-0.82; Figure 2). Revised observed relapse rates were $29.7 \%$ for cariprazine vs $49.5 \%$ for placebo, for a NNT of six (95\% CI 3-16). These NNT values are similar to what has been reported for other first-line second-generation antipsychotics. ${ }^{70}$

As reported in the original analysis, ${ }^{19}$ the 25 th percentile for time to relapse was 92 days in the placebo group and 224 days in the cariprazine group. The 50th percentile (median) was 296 days for the placebo group and could not be calculated for the cariprazine group, because of the low number of relapse events. Of note, between-group separation of the curves did not occur until around day 50, possibly because of the long half-life of cariprazine (and specifically DDCAR), lending some extended protection against the risk of relapse, similar to what was observed when examining this phenomenon in similarly designed randomized-withdrawal studies conducted for paliperidone extended release oral vs 1-month paliperidone palmitate vs 3-month paliperidone palmitate. ${ }^{71}$ 


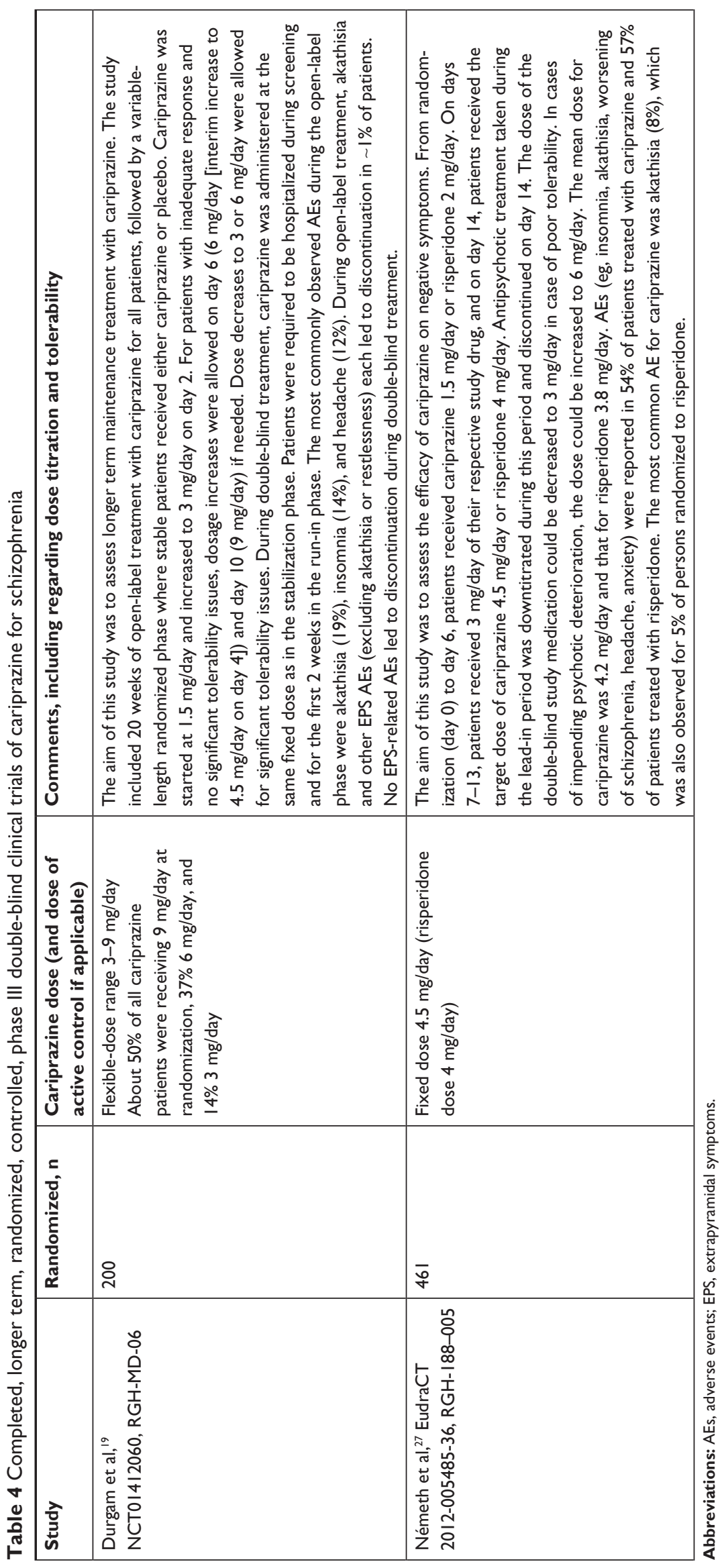




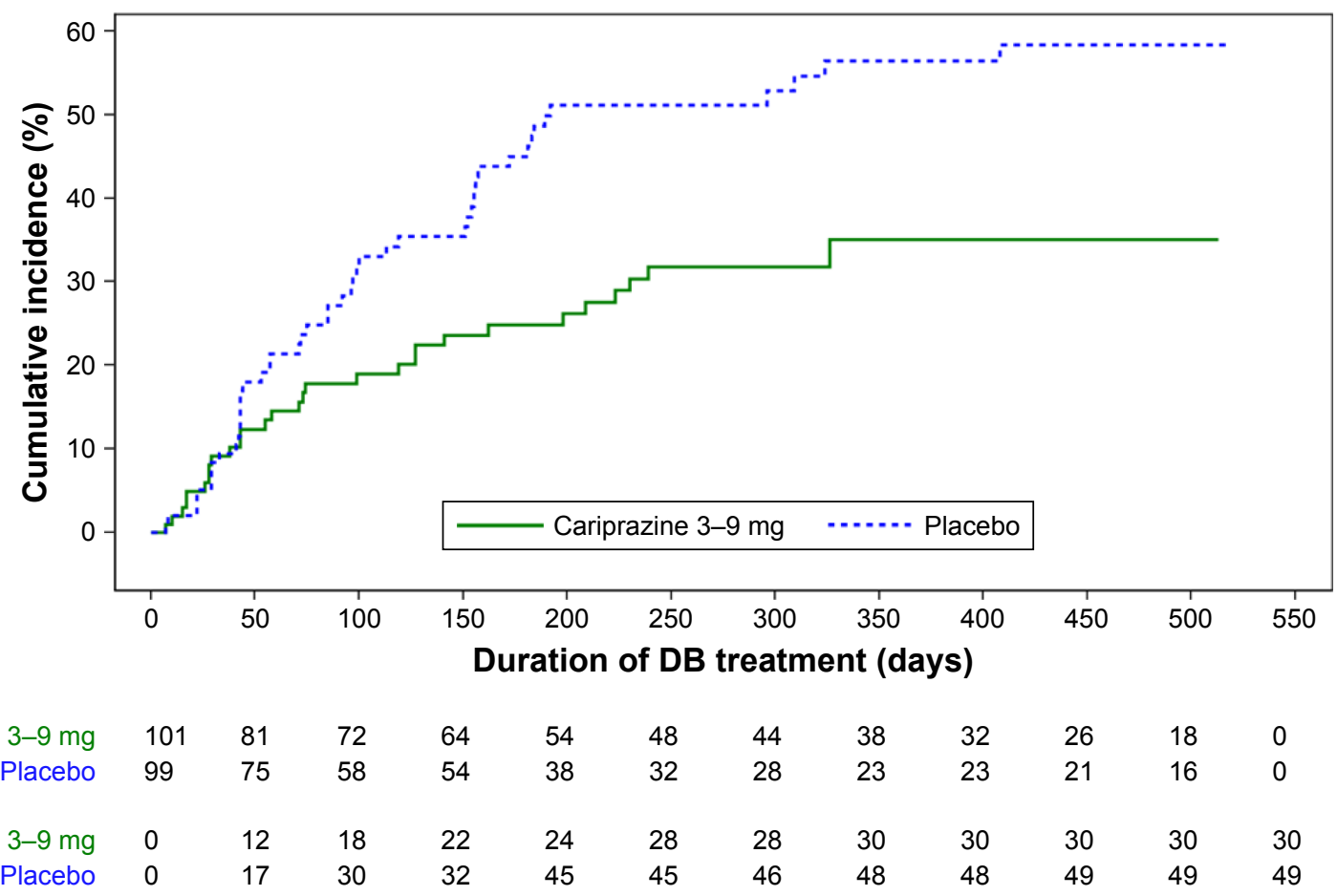

Figure 2 Kaplan-Meier curves of cumulative rate of relapse during the double-blind treatment period.

Notes: Reproduced from the product label. ${ }^{10}$ Although the study permitted dosing of cariprazine at 3-9 mg/day, the maximum recommended daily dose is 6 mg. Betweengroup separation of the curves did not occur until around day 50, possibly because of the long half-life of cariprazine (and specifically DDCAR) lending some extended protection against the risk of relapse.

Abbreviations: DB, double-blind; DDCAR, didesmethyl-cariprazine.

The most commonly observed adverse events during the open-label phase were akathisia (19\%), insomnia (14\%), and headache (12\%). During open-label treatment, akathisia and other EPS adverse events (excluding akathisia or restlessness) each led to discontinuation in $\sim 1 \%$ of patients, while no EPSrelated adverse events led to discontinuation during doubleblind treatment. Changes from baseline in lipid parameters at the end of open-label and double-blind treatment were generally not clinically relevant. There were no clinically relevant mean changes in blood pressure, and no patient had a QTc of $>500 \mathrm{~ms}$. Weight gain $\geq 7 \%$ was reported in $11 \%$ of open-label patients, and in $32 \%$ of placebo-treated patients and $27 \%$ of cariprazine-treated patients during double-blind treatment.

\section{Negative symptoms}

Cariprazine's European product label, the summary of product characteristics, ${ }^{72}$ includes support for cariprazine's efficacy for the treatment of predominantly negative symptoms in patients with schizophrenia based on a 26-week doubleblind randomized study comparing cariprazine $4.5 \mathrm{mg}$ /day with risperidone $4 \mathrm{mg} /$ day in 460 nonelderly adult patients. ${ }^{27}$ See also Table 4 . There was no placebo control. In this study, patients were required to have a PANSS negative-factor score $^{73}$ (NFS) $\geq 24$, with single-item scores of at least moderate on selected symptoms, such as blunted affect, passive/ apathetic social withdrawal, and lack of spontaneity and flow of conversation. Excluded were patients with a hospital admission or an acute exacerbation of schizophrenia within the last 6 months prior to the study, a PANSS positive-factor score $>19$, significant positive- or negative-symptom fluctuations (ie, instability) during the prospective lead-in period, treatment with clozapine in the 12 months prior to the study, moderate-severe depressive symptoms, clinically relevant parkinsonian symptoms, or treatment with antidepressant medications and/or anticholinergic medications used to treat abnormal movements. After randomization, patients were uptitrated in 2 weeks to the target dose of cariprazine $4.5 \mathrm{mg}$ /day or risperidone $4 \mathrm{mg} /$ day, but at the end of week 3 and at every subsequent visit, the dose of the double-blind study medication could be decreased to $3 \mathrm{mg}$ /day in cases of poor tolerability. In cases of impending psychotic deterioration, the dose could be increased to $6 \mathrm{mg} / \mathrm{day}$.

Mean age was 40 years, and $57 \%$ of patients were male. Overall, $77 \%$ of patients completed the double-blind treatment period. The mean daily dose for cariprazine was $4.2 \mathrm{mg}$ and that for risperidone $3.8 \mathrm{mg}$. The modal dose (excluding the uptitration period) was the target dose (ie, $4.5 \mathrm{mg} /$ day 
for cariprazine and $4 \mathrm{mg} /$ day for risperidone) for $95 \%$ of patients treated with either antipsychotic. Cariprazine was superior to risperidone on both the primary (PANSS-NFS) and key secondary outcomes (Personal and Social Performance Scale). PANSS-NFS responder rates at week 26 (as defined by $\geq 20 \%$ decrease in baseline score) were $69 \%$ for cariprazine vs $58 \%$ for risperidone, resulting in a NNT of nine (95\% CI 5-44). For outcome variables analyzed to assess pseudospecific effects (change from baseline for PANSS positive symptoms, depression, and parkinsonian symptoms), changes were small and similar for cariprazine and risperidone. These results thus excluded indirect effects related to positive, depressive, or EPS improvement as a factor in negative-symptom improvement. Quality-adjusted life-year gain was also modeled, and resulted in an estimated quality-adjusted life-year gain of 0.029 per patient after 1 year of treatment. ${ }^{28}$ The most common adverse event for cariprazine was akathisia ( $8 \%$, which was also observed for $5 \%$ of persons randomized to risperidone.

\section{Conclusion}

Cariprazine is notable for being a dopamine-receptor partial agonist with a tenfold higher affinity for dopamine $\mathrm{D}_{3}$ vs $\mathrm{D}_{2}$ receptors, ${ }^{10,13,30}$ this differs from other available antipsychotics, and has theoretical advantages in people with schizophrenia based on preclinical data. This is also supported by a single study ${ }^{27}$ demonstrating superiority over risperidone in the treatment of predominantly negative symptoms in patients with schizophrenia; however, the effect size was small and the study requires replication. Cariprazine is also approved in the US for the acute treatment of manic or mixed episodes associated with bipolar I disorder in adults. ${ }^{10,26,53-59}$ An active clinical development plan includes studies in bipolar I depression ${ }^{60}$ and major depressive disorder. ${ }^{61}$

Cariprazine also differs from other oral antipsychotics in terms of the extended half-life of its major active metaboliteDDCAR. ${ }^{10,18}$ DDCAR is the predominant circulating moiety, representing about $70 \%$ of the total exposure. An extended half-life carries important implications for dosing, as rapid increases in dose may be premature and possibly result in poorer tolerability. A long half-life also makes the interpretation of the short-term acute trials more difficult, as steady state is not reached for some time and changes in dose will not be fully reflected in plasma for several weeks. ${ }^{10}$ However, a long half-life may provide a degree of protection when doses are occasionally missed. In the randomized-withdrawal relapse study, ${ }^{19}$ between-group separation of the curves did not occur until around day 50. Of note, cariprazine is the only antipsychotic with instructions allowing dosing every other day $(1.5 \mathrm{mg} /$ day for coadministration with a CYP3A4 inhibitor). Under usual circumstances for patients with schizophrenia, the recommended dose range is $1.5-6 \mathrm{mg}$ once daily, with a starting dose of $1.5 \mathrm{mg}$ once daily with or without food. The product label does not provide guidance as to a preferred time of day when cariprazine should be administered. As described in detail earlier, the maximum

Table $5 \mathrm{NNH}$ vs placebo for approved first-line oral second-generation antipsychotics in adults, as observed in acute short-term studies for schizophrenia ${ }^{a}$

\begin{tabular}{|c|c|c|c|c|c|c|c|}
\hline Antipsychotic & $\begin{array}{l}\text { NNH for } \\
\text { weight } \\
\text { gain } \geq 7 \%\end{array}$ & $\begin{array}{l}\text { Rank } \\
\text { order }\end{array}$ & $\begin{array}{l}\text { NNH for } \\
\text { somnolence } \\
\text { adverse events }\end{array}$ & Rank & $\begin{array}{l}\text { NNH for } \\
\text { akathisia } \\
\text { adverse events }\end{array}$ & Rank & $\begin{array}{l}\text { Average } \\
\text { of ranking } \\
\text { values }\end{array}$ \\
\hline Cariprazine (to 6 mg/day) & 34 & 3 & $100^{\mathrm{b}}$ & 1 & 15 & 8 & 4.0 \\
\hline Brexpiprazole & 17 & 7 & $50^{\mathrm{b}}$ & 2 & 112 & 3 & 4.0 \\
\hline Aripiprazole & 21 & 5 & $20^{c}$ & 4 & 25 & 7 & 5.3 \\
\hline Risperidone (to $8 \mathrm{mg} /$ day) & $18^{c}$ & 6 & 13 & 8 & 15 & 8 & 4.7 \\
\hline Olanzapine & $6^{c}$ & 10 & $7^{c}$ & 11 & 25 & 7 & 9.3 \\
\hline Quetiapine immediate release & 6 & 10 & $10^{c}$ & 10 & NA & 1 & 7.0 \\
\hline Quetiapine extended release & 22 & 4 & 7 & 11 & 188 & 2 & 5.7 \\
\hline Ziprasidone & 16 & 8 & 15 & 7 & 100 & 4 & 6.3 \\
\hline Paliperidone & 35 & 2 & 42 & 3 & 39 & 5 & 3.3 \\
\hline Iloperidone & 10 & 9 & 16 & 6 & NA & $\mathrm{I}$ & 5.3 \\
\hline Asenapine & 35 & 2 & 17 & 5 & 34 & 6 & 4.3 \\
\hline Lurasidone & 67 & I & 11 & 9 & 10 & 9 & 6.3 \\
\hline
\end{tabular}

Notes: aTable adapted (NNH values extracted)," with permission; bsomnolence, sedation, hypersomnia; 'reported in product labeling for schizophrenia and bipolar mania pooled together.

Abbreviations: NA, not applicable (no difference or rate with medication lower than rate with placebo); NNH, number needed to harm. 
recommended daily dose is $6 \mathrm{mg}$ based on observations made during the short-term controlled trials, where dosages $>6 \mathrm{mg}$ daily did not confer increased effectiveness sufficient to outweigh dose-related adverse reactions.

Overall tolerability is promising, with the rate of discontinuation due to adverse events lower than that observed for placebo in the acute trials for schizophrenia. ${ }^{14-17,24}$ Elevations in prolactin were not observed, and no clinically relevant effects on the electrocardiographic QT interval were evident. As with all second-generation antipsychotics, monitoring individual patients for alterations in weight and metabolic shifts is necessary. ${ }^{74}$ Using data from prior analyses, ${ }^{8,11}$ Table 5 provides ranking of $\mathrm{NNH}$ values for clinically relevant weight gain, adverse events of somnolence, and adverse events of akathisia vs placebo for all first-line second-generation oral antipsychotics, as observed in shortterm studies in adults for schizophrenia and calculated from product labeling. Except for akathisia, cariprazine appears to have favorable (ie, higher) NNH values than some of the other agents. Of interest are the NNH values for somnolence, where cariprazine appears best in class with a ranking of 1 . When contrasting the three available dopamine-receptor partial agonists, the order of propensity for weight gain appears to be brexpiprazole $>$ aripiprazole $>$ cariprazine, propensity for somnolence aripiprazole $>$ brexpiprazole $>$ cariprazine, and propensity for akathisia cariprazine $>$ aripiprazole $>$ brexpiprazole. These indirect comparisons will need to be confirmed by appropriately designed headto-head clinical trials. ${ }^{8}$ The averages of the ranking values are also shown (lower numbers are best) and give an idea of overall tolerability for each antipsychotic. Although most of the antipsychotics have similar average ranking values, an individual patient's concerns for each of the different tolerability items would likely influence the choices considered acceptable, and in any event weighed against efficacy considerations for that individual patient. ${ }^{3}$ An additional caveat is that the adverse-event rates reported here do not take into account severity or duration of the event: short-lived and perhaps easily manageable adverse events will be less likely problematic than adverse events such as weight gain, which can be persistent and more difficult to ameliorate. Another caveat is that adverse-event rates, and thus the NNH values derived from them, can vary by therapeutic indication. ${ }^{75,76}$

In general, despite the availability of many antipsychotics for the treatment of schizophrenia, this disorder is complex and often difficult to treat. As noted, antipsychotics vary in terms of tolerability and safety concerns, ${ }^{2}$ and patients themselves differ in terms of preexisting risk factors and comorbidities, which make drug selection challenging. 5,77 Having an additional choice is welcome.

\section{Acknowledgments}

No external funding or writing assistance from any source was used in the creation of this review. The manufacturer (Allergan) had no involvement in terms of funding or review of this manuscript.

\section{Disclosure}

In the past 12 months, the author has acted as a consultant for Acadia, Alkermes, Allergan, Intra-Cellular Therapies, Janssen, Lundbeck, Merck, Neurocrine, Noven, Otsuka, Pfizer, Shire, Sunovion, Takeda, Teva, and Vanda; as a speaker for Acadia, Alkermes, Allergan, Janssen, Lundbeck, Merck, Neurocrine, Otsuka, Pfizer, Shire, Sunovion, Takeda, and Teva; and has received royalties from Wiley (editor-inchief, International Journal of Clinical Practice), UpToDate (reviewer), and Springer Healthcare (book). The author holds stocks (small number of shares of common stock) in Bristol-Myers Squibb, Eli Lilly, Johnson \& Johnson, Merck, and Pfizer (purchased $>10$ years ago). The author reports no other conflicts of interest in this work.

\section{References}

1. Citrome L. Emerging pharmacological therapies in schizophrenia: what's new, what's different, what's next? CNS Spectr. 2016;21(S1):1-12.

2. Leucht S, Cipriani A, Spineli L, et al. Comparative efficacy and tolerability of 15 antipsychotic drugs in schizophrenia: a multiple-treatments meta-analysis. Lancet. 2013;382(9896):951-962.

3. Volavka J, Citrome L. Oral antipsychotics for the treatment of schizophrenia: heterogeneity in efficacy and tolerability should drive decisionmaking. Expert Opin Pharmacother. 2009;10(12):1917-1928.

4. Citrome L. Unmet needs in the treatment of schizophrenia: new targets to help different symptom domains. J Clin Psychiatry. 2014;75(Suppl 1): 21-26.

5. Citrome L, Eramo A, Francois C, et al. Lack of tolerable treatment options for patients with schizophrenia. Neuropsychiatr Dis Treat. 2015;11:3095-3104.

6. FDA. Cariprazine Drug Approval Package; 2015. Available from: http://www.accessdata.fda.gov/drugsatfda_docs/nda/2015/ 204370Orig2s000TOC.cfm. Accessed July 4, 2018.

7. European Medicines Agency. Reagila Assessment Report; 2017. Available from: http://www.ema.europa.eu/docs/en_GB/document_library/ EPAR_-_Public_assessment_report/human/002770/WC500234926. pdf. Accessed July 4, 2018.

8. Citrome L. The ABC's of dopamine receptor partial agonists aripiprazole, brexpiprazole and cariprazine: the 15-min challenge to sort these agents out. Int J Clin Pract. 2015;69(11):1211-1220.

9. Citrome L. Aripiprazole, brexpiprazole, and cariprazine: not all the same. Current Psychiatry. 2018;17(4):24-33, 43.

10. Allergan. VRAYLAR (cariprazine) capsules, for oral use; 2017. Available from: https://www.allergan.com/assets/pdf/vraylar_pi. Accessed July 4, 2018.

11. Citrome L. Cariprazine for the Treatment of Schizophrenia: A Review of this Dopamine $\mathrm{D}_{3}$-Preferring $\mathrm{D}_{3} / \mathrm{D}_{2}$ Receptor Partial Agonist. Clin Schizophr Relat Psychoses. 2016;10(2):109-119. 
12. Citrome L. Cariprazine in schizophrenia: clinical efficacy, tolerability, and place in therapy. Adv Ther. 2013;30(2):114-126.

13. Citrome L. Cariprazine: chemistry, pharmacodynamics, pharmacokinetics, and metabolism, clinical efficacy, safety, and tolerability. Expert Opin Drug Metab Toxicol. 2013;9(2):193-206.

14. Durgam S, Litman RE, Papadakis K, Li D, Németh G, Laszlovszky I. Cariprazine in the treatment of schizophrenia: a proof-of-concept trial. Int Clin Psychopharmacol. 2016;31(2):61-68.

15. Durgam S, Starace A, Li D, et al. An evaluation of the safety and efficacy of cariprazine in patients with acute exacerbation of schizophrenia: a phase II, randomized clinical trial. Schizophr Res. 2014;152(2-3): $450-457$.

16. Kane JM, Zukin S, Wang Y, et al. Efficacy and Safety of cariprazine in acute exacerbation of schizophrenia: results from an international, Phase III clinical trial. J Clin Psychopharmacol. 2015;35(4):367-373.

17. Durgam S, Cutler AJ, Lu K, et al. Cariprazine in acute exacerbation of schizophrenia: a fixed-dose, phase 3, randomized, double-blind, placebo- and active-controlled trial. J Clin Psychiatry. 2015;76(12):e1574-e1582.

18. Nakamura T, Kubota T, Iwakaji A, Imada M, Kapás M, Morio Y. Clinical pharmacology study of cariprazine (MP-214) in patients with schizophrenia (12-week treatment). Drug Des Devel Ther. 2016;10:327-338.

19. Durgam S, Earley W, Li R, et al. Corrigendum to "Long-term cariprazine treatment for the prevention of relapse in patients with schizophrenia: A randomized, double-blind, placebo-controlled trial" [Schizophr. Res. 176 (2016) 264-271]. Schizophr Res. 2018;192:493.

20. Earley W, Guo H, Luchini R. Modified cariprazine relapse prevention clinical trial results. Schizophr Res. Epub 2018 Apr 26.

21. Durgam S, Greenberg WM, Li D, et al. Safety and tolerability of cariprazine in the long-term treatment of schizophrenia: results from a 48-week, single-arm, open-label extension study. Psychopharmacology. 2017;234(2):199-209.

22. Cutler AJ, Durgam S, Wang Y, et al. Evaluation of the long-term safety and tolerability of cariprazine in patients with schizophrenia: results from a 1-year open-label study. CNS Spectr. 2018;23(1):39-50.

23. Nasrallah HA, Earley W, Cutler AJ, et al. The safety and tolerability of cariprazine in long-term treatment of schizophrenia: a post hoc pooled analysis. BMC Psychiatry. 2017;17(1):305.

24. Earley W, Durgam S, Lu K, Laszlovszky I, Debelle M, Kane JM. Safety and tolerability of cariprazine in patients with acute exacerbation of schizophrenia: a pooled analysis of four phase II/III randomized, double-blind, placebo-controlled studies. Int Clin Psychopharmacol. 2017;32(6):319-328.

25. Citrome L, Durgam S, Lu K, Ferguson P, Laszlovszky I. The effect of cariprazine on hostility associated with schizophrenia: post hoc analyses from 3 randomized controlled trials. J Clin Psychiatry. 2016;77(1):109-115.

26. Durgam S, Earley W, Lu K, et al. Global improvement with cariprazine in the treatment of bipolar I disorder and schizophrenia: a pooled post hoc analysis. Int J Clin Pract. 2017;71(12):e13037.

27. Németh G, Laszlovszky I, Czobor P, et al. Cariprazine versus risperidone monotherapy for treatment of predominant negative symptoms in patients with schizophrenia: a randomised, double-blind, controlled trial. Lancet. 2017;389(10074):1103-1113.

28. Németh B, Molnár A, Akehurst R, et al. Quality-adjusted life year difference in patients with predominant negative symptoms of schizophrenia treated with cariprazine and risperidone. J Comp Eff Res. 2017; 6(8):639-648.

29. Mészáros GP, Agai-Csongor E, Kapás M. Sensitive LC-MS/MS methods for the quantification of RGH-188 and its active metabolites, desmethyl- and didesmethyl-RGH-188 in human plasma and urine. J Pharm Biomed Anal. 2008;48(2):388-397.

30. Kiss B, Horváth A, Némethy Z, et al. Cariprazine (RGH-188), a dopamine $\mathrm{D}(3)$ receptor-preferring, $\mathrm{D}(3) / \mathrm{D}(2)$ dopamine receptor antagonist-partial agonist antipsychotic candidate: in vitro and neurochemical profile. J Pharmacol Exp Ther. 2010;333(1):328-340.

31. Seneca N, Finnema SJ, Laszlovszky I, et al. Occupancy of dopamine $\mathrm{D}_{2}$ and $\mathrm{D}_{3}$ and serotonin 5-HT $\mathrm{A}$ receptors by the novel antipsychotic drug candidate, cariprazine (RGH-188), in monkey brain measured using positron emission tomography. Psychopharmacology. 2011;218(3):579-587.
32. Gyertyán I, Kiss B, Sághy K, et al. Cariprazine (RGH-188), a potent $\mathrm{D}_{3} / \mathrm{D}_{2}$ dopamine receptor partial agonist, binds to dopamine $\mathrm{D}_{3}$ receptors in vivo and shows antipsychotic-like and procognitive effects in rodents. Neurochem Int. 2011;59(6):925-935.

33. Tadori Y, Forbes RA, Mcquade RD, Kikuchi T. In vitro pharmacology of aripiprazole, its metabolite and experimental dopamine partial agonists at human dopamine $\mathrm{D}_{2}$ and $\mathrm{D}_{3}$ receptors. Eur J Pharmacol. 2011;668(3):355-365.

34. Agai-Csongor E, Domány G, Nógrádi K, et al. Discovery of cariprazine (RGH-188): a novel antipsychotic acting on dopamine $\mathrm{D}_{3} / \mathrm{D}_{2}$ receptors. Bioorg Med Chem Lett. 2012;22(10):3437-3440.

35. Zimnisky R, Chang G, Gyertyán I, Kiss B, Adham N, Schmauss C. Cariprazine, a dopamine $\mathrm{D}(3)$-receptor-preferring partial agonist, blocks phencyclidine-induced impairments of working memory, attention setshifting, and recognition memory in the mouse. Psychopharmacology. 2013;226(1):91-100.

36. Román V, Gyertyán I, Sághy K, Kiss B, Szombathelyi Z. Cariprazine (RGH-188), a $\mathrm{D}_{3}$-preferring dopamine $\mathrm{D}_{3} / \mathrm{D}_{2}$ receptor partial agonist antipsychotic candidate demonstrates anti-abuse potential in rats. Psychopharmacology. 2013;226(2):285-293.

37. Tóth $\mathrm{M}$, Varrone A, Steiger C, et al. Brain uptake and distribution of the dopamine $\mathrm{D}_{3} / \mathrm{D}_{2}$ receptor partial agonist $[11 \mathrm{C}]$ cariprazine: an in vivo positron emission tomography study in nonhuman primates. Synapse. 2013;67(5):258-264.

38. Shonberg J, Herenbrink CK, López L, et al. A structure-activity analysis of biased agonism at the dopamine $\mathrm{D}_{2}$ receptor. $J$ Med Chem. 2013;56(22):9199-9221.

39. Papp M, Gruca P, Lasoń-Tyburkiewicz M, Adham N, Kiss B, Gyertyán I. Attenuation of anhedonia by cariprazine in the chronic mild stress model of depression. Behav Pharmacol. 2014;25(5-6):567-574.

40. Choi YK, Adham N, Kiss B, Gyertyán I, Tarazi FI. Long-term effects of cariprazine exposure on dopamine receptor subtypes. CNS Spectr. 2014;19(3):268-277.

41. Hendrick CE, Wang Q. Synthesis of ortho-haloaminoarenes by aryne insertion of nitrogen-halide bonds. J Org Chem. 2015;80(2):1059-1069.

42. El-Mallakh RS, Payne RS, Schurr A, et al. Cariprazine delays ouabainevoked epileptiform spikes and loss of activity in rat hippocampal slices. Psychiatry Res. 2015;229(1-2):370-373.

43. Gao Y, Peterson S, Masri B, et al. Cariprazine exerts antimanic properties and interferes with dopamine $\mathrm{D}_{2}$ receptor $\beta$-arrestin interactions. Pharmacol Res Perspect. 2015;3(1):e0073.

44. Neill JC, Grayson B, Kiss B, Gyertyán I, Ferguson P, Adham N. Effects of cariprazine, a novel antipsychotic, on cognitive deficit and negative symptoms in a rodent model of schizophrenia symptomatology. Eur Neuropsychopharmacol. 2016;26(1):3-14.

45. Girgis RR, Slifstein M, D'Souza D, et al. Preferential binding to dopamine $\mathrm{D}_{3}$ over $\mathrm{D}_{2}$ receptors by cariprazine in patients with schizophrenia using PET with the $\mathrm{D}_{3} / \mathrm{D}_{2}$ receptor ligand [(11)C]-(+)-PHNO. Psychopharmacology. 2016;233(19-20):3503-3512.

46. Watson DJG, King MV, Gyertyán I, Kiss B, Adham N, Fone KCF. The dopamine $\mathrm{D}_{3}$-preferring $\mathrm{D}_{2} / \mathrm{D}_{3}$ dopamine receptor partial agonist, cariprazine, reverses behavioural changes in a rat neurodevelopmental model for schizophrenia. Eur Neuropsychopharmacol. 2016;26(2):208-224.

47. Duric V, Banasr M, Franklin T, et al. Cariprazine Exhibits Anxiolytic and Dopamine $\mathrm{D}_{3}$ Receptor-Dependent Antidepressant Effects in the Chronic Stress Model. Int J Neuropsychopharmacol. 2017;20(10):788-796.

48. Choi YK, Adham N, Kiss B, Gyertyán I, Tarazi FI. Long-term effects of aripiprazole exposure on monoaminergic and glutamatergic receptor subtypes: comparison with cariprazine. CNS Spectr. 2017;22(6):484-494.

49. Barnes SA, Young JW, Markou A, Adham N, Gyertyán I, Kiss B. The Effects of Cariprazine and Aripiprazole on PCP-Induced Deficits on Attention Assessed in the 5-Choice Serial Reaction Time Task. Psychopharmacology. 2018;235(55):1403-1414.

50. Kehr J, Yoshitake T, Ichinose F, et al. Effects of cariprazine on extracellular levels of glutamate, GABA, dopamine, noradrenaline and serotonin in the medial prefrontal cortex in the rat phencyclidine model of schizophrenia studied by microdialysis and simultaneous recordings of locomotor activity. Psychopharmacology. 2018;235(5):1593-1607. 
51. Genaro-Mattos TC, Tallman KA, Allen LB, et al. Dichlorophenyl piperazines, including a recently-approved atypical antipsychotic, are potent inhibitors of DHCR7, the last enzyme in cholesterol biosynthesis. Toxicol Appl Pharmacol. 2018;349:21-28.

52. Delcourte S, Ashby CR, Rovera R, et al. The novel atypical antipsychotic cariprazine demonstrates dopamine $\mathrm{D}_{2}$ receptor-dependent partial agonist actions on rat mesencephalic dopamine neuronal activity. CNS Neurosci Ther. Epub 2018 May 4.

53. Durgam S, Starace A, Li D, et al. The efficacy and tolerability of cariprazine in acute mania associated with bipolar I disorder: a phase II trial. Bipolar Disord. 2015;17(1):63-75.

54. Sachs GS, Greenberg WM, Starace A, et al. Cariprazine in the treatment of acute mania in bipolar I disorder: a double-blind, placebo-controlled, phase III trial. J Affect Disord. 2015;174:296-302.

55. Calabrese JR, Keck PE, Starace A, et al. Efficacy and safety of low- and high-dose cariprazine in acute and mixed mania associated with bipolar I disorder: a double-blind, placebo-controlled study. J Clin Psychiatry. 2015;76(3):284-292.

56. Ketter TA, Sachs GS, Durgam S, et al. The safety and tolerability of cariprazine in patients with manic or mixed episodes associated with bipolar I disorder: a 16-week open-label study. J Affect Disord. 2018;225: 350-356.

57. Earley W, Durgam S, Lu K, et al. Tolerability of cariprazine in the treatment of acute bipolar I mania: a pooled post hoc analysis of 3 phase II/III studies. J Affect Disord. 2017;215:205-212.

58. Vieta E, Durgam S, Lu K, Ruth A, Debelle M, Zukin S. Effect of cariprazine across the symptoms of mania in bipolar I disorder: analyses of pooled data from phase II/III trials. Eur Neuropsychopharmacol. 2015;25(11):1882-1891

59. Earley W, Durgam S, Lu K, et al. Clinically relevant response and remission outcomes in cariprazine-treated patients with bipolar I disorder. J Affect Disord. 2018;226:239-244.

60. Durgam S, Earley W, Lipschitz A, et al. An 8-week randomized, double-blind, placebo-controlled evaluation of the safety and efficacy of cariprazine in patients with bipolar I depression. Am J Psychiatry. 2016;173(3):271-281

61. Durgam S, Earley W, Guo H, et al. Efficacy and safety of adjunctive cariprazine in inadequate responders to antidepressants: a randomized, double-blind, placebo-controlled study in adult patients with major depressive disorder. J Clin Psychiatry. 2016;77(3):371-378.

62. Lao KS, He Y, Wong IC, Besag FM, Chan EW. Tolerability and Safety Profile of Cariprazine in Treating Psychotic Disorders, Bipolar Disorder and Major Depressive Disorder: A Systematic Review with Meta-Analysis of Randomized Controlled Trials. CNS Drugs. 2016;30(11):1043-1054.

63. Corponi F, Serretti A, Montgomery S, Fabbri C. Cariprazine specificity profile in the treatment of acute schizophrenia: a meta-analysis and meta-regression of randomized-controlled trials. Int Clin Psychopharmacol. 2017;32(6):309-318.
64. Zhao MJ, Qin B, Wang JB, et al. Efficacy and Acceptability of Cariprazine in Acute Exacerbation of Schizophrenia: Meta-Analysis of Randomized Placebo-Controlled Trials. J Clin Psychopharmacol. 2018;38(1):55-59.

65. Meyer JM, Loebel AD, Schweizer E. Lurasidone: a new drug in development for schizophrenia. Expert Opin Investig Drugs. 2009;18(11): 1715-1726.

66. Stahl SM. Drugs for psychosis and mood: unique actions at $\mathrm{D}_{3}, \mathrm{D}_{2}$, and D1 dopamine receptor subtypes. CNS Spectr. 2017;22(5):375-384.

67. Stahl SM. Dazzled by the dominions of dopamine: clinical roles of $\mathrm{D}_{3}$, $\mathrm{D}_{2}$, and D1 receptors. CNS Spectr. 2017;22(4):305-311.

68. Shaye K, Amir T, Shlomo S, Yechezkel S. Fasting glucose levels within the high normal range predict cardiovascular outcome. Am Heart J. 2012;164(1):111-116.

69. Allergan. Allergan Receives FDA Approval For Use of VRAYLAR (cariprazine) in the Maintenance Treatment of Schizophrenia; 2017. Available from: https://www.allergan.com/news/news/thomson-reuters/ allergan-receives-fda-approval-for-use-of-vraylar. Accessed July 6, 2018.

70. Citrome L. Schizophrenia relapse, patient considerations, and potential role of lurasidone. Patient Prefer Adherence. 2016;10:1529-1537.

71. Weiden PJ, Kim E, Bermak J, Turkoz I, Gopal S, Berwaerts J. Does Half-Life Matter After Antipsychotic Discontinuation? A Relapse Comparison in Schizophrenia With 3 Different Formulations of Paliperidone. J Clin Psychiatry. 2017;78(7):e813-e820.

72. European Medicines Agency. Reagila Summary of Product Characteristics. Available from: http://www.ema.europa.eu/docs/en_GB document_library/EPAR_-_Product_Information/human/002770/ WC500234924.pdf. Accessed July 6, 2018.

73. Edgar CJ, Blaettler T, Bugarski-Kirola D, Le Scouiller S, Garibaldi GM, Marder SR. Reliability, validity and ability to detect change of the PANSS negative symptom factor score in outpatients with schizophrenia on select antipsychotics and with prominent negative or disorganized thought symptoms. Psychiatry Res. 2014;218(1-2):219-224.

74. Citrome L, Nasrallah HA. On-label on the table: what the package insert informs us about the tolerability profile of oral atypical antipsychotics, and what it does not. Expert Opin Pharmacother. 2012;13(11):1599-1613.

75. Citrome L. Quantifying risk: the role of absolute and relative measures in interpreting risk of adverse reactions from product labels of antipsychotic medications. Curr Drug Saf. 2009;4(3):229-237.

76. Citrome L. Activating and Sedating Adverse Effects of Second-Generation Antipsychotics in the Treatment of Schizophrenia and Major Depressive Disorder: Absolute Risk Increase and Number Needed to Harm. J Clin Psychopharmacol. 2017;37(2):138-147.

77. Citrome L, Johnston S, Nadkarni A, Sheehan JJ, Kamat SA, Kalsekar I. Prevalence of pre-existing risk factors for adverse events associated with atypical antipsychotics among commercially insured and Medicaid insured patients newly initiating atypical antipsychotics. Curr Drug Saf. 2014;9(3):227-235.
Neuropsychiatric Disease and Treatment

\section{Publish your work in this journal}

Neuropsychiatric Disease and Treatment is an international, peerreviewed journal of clinical therapeutics and pharmacology focusing on concise rapid reporting of clinical or pre-clinical studies on a range of neuropsychiatric and neurological disorders. This journa is indexed on PubMed Central, the 'PsycINFO' database and CAS,

\section{Dovepress}

and is the official journal of The International Neuropsychiatric Association (INA). The manuscript management system is completely online and includes a very quick and fair peer-review system, which is all easy to use. Visit http://www.dovepress.com/testimonials.php to read real quotes from published authors. 